\title{
REVIEW
}

\section{Clinical review: Fever in septic ICU patients - friend or foe?}

Yoann Launey ${ }^{1,2,3}$, Nicolas Nesseler, ${ }^{1,2,3}$, Yannick Mallédant ${ }^{1,2,3 *}$ and Philippe Seguin ${ }^{1,2,3}$

\begin{abstract}
In recent years, fever control in critically ill patients by medications and/or external cooling has gained widespread use, notably in patients suffering from neurological injuries. Nevertheless, such a strategy in septic patients is not supported by relevant data. Indeed, in response to sepsis, experimental and clinical studies argue that fever plays a key role in increasing the clearance of microorganisms, the immune response and the heat shock response. Moreover, fever is a cornerstone diagnostic sign in clinical practice, which aids in early and appropriate therapy, and allows physicians to follow the infection course. After discussing the physiological aspects of fever production, the present review aims to delineate the advantages and drawbacks of fever in septic patients. Finally, the treatment of fever by pharmacological and/ or physical means is discussed with regards to their drawbacks, which argues for their careful use in septic patients in the absence of clinical relevance.
\end{abstract}

\section{Introduction}

Fever is a nonspecific response to various types of infectious or non-infectious stimuli. The incidence in ICUs ranges from 23 to $70 \%$ and is related to an infectious process in only one-half of the cases [1-3]. In the past two decades, numerous studies have underlined the deleterious effects of fever on outcome, especially in neurological diseases, leading to active treatment of fever with medications and/or various physical means [4]. However, the rationale for extending such a strategy to septic patients is not supported by clinical data, and several lines of evidence suggest that fever in these patients may be helpful to fight the infectious process. Some practices,

*Correspondence: yannick.malledant@chu-rennes.fr

'Service d'Anesthésie-Réanimation 1, Hôpital Pontchaillou, 2 rue Henri Le Guilloux, 35000 Rennes, France

Full list of author information is available at the end of the article such as fever-induced discomfort and/or favoured febrile seizures, have been reconsidered [5-8]. Moreover, fever is a cornerstone diagnostic sign in clinical practice that helps to start early appropriate therapy and to follow the infection course. Besides, sepsis biomarkers (that is, procalcitonin, C-reactive protein) have to prove their relevance [9]. Finally, antipyretic therapies have side effects that must be taken into account when physicians decide to control fever.

The objective of the present review is to delineate the advantages and drawbacks of fever in septic patients. The main side effects of antipyretic therapies are also emphasised.

\section{Definition and pathophysiology of fever}

The core body temperature is tightly regulated around a set point by homeostatic mechanisms under normal physiological conditions. Nevertheless, there is a female hormonal-induced variation and a diurnal variation. So, Mackowiak and colleagues found that the mean temperature was $36.8^{\circ} \mathrm{C}$, with a range of 35.6 to $38.2^{\circ} \mathrm{C}$, the temperature being lower in the morning than in the evening [1].

Fever is an upregulation of the hypothalamic temperature and is often difficult to differentiate from hyperthermic syndromes. In the latter, the setpoint remains unchanged but involves a dysregulation of peripheral mechanisms of heat production or loss. The threshold value of fever differs between epidemiological ICU studies, ranging from 38.3 to $38.5^{\circ} \mathrm{C}[2,10,11]$, but a threshold value of $\geq 38.3^{\circ} \mathrm{C}$ has been recommended by several societies for the diagnosis of fever [12,13]. This definition has to be considered with regards to the methods used to determine the temperature. Indeed, the core temperature is important as a core to peripheral temperature gradient is common in critically ill patients, especially in those who are hypovolaemic, have a low cardiac output or are peripherally vasoconstricted. In the ICU, the temperature reference is provided by the thermistance of the pulmonary artery catheter, but most of the patients have no such device in place. In addition, comparison with other methods of temperature measurement is far from being well correlated. Accordingly, it has 


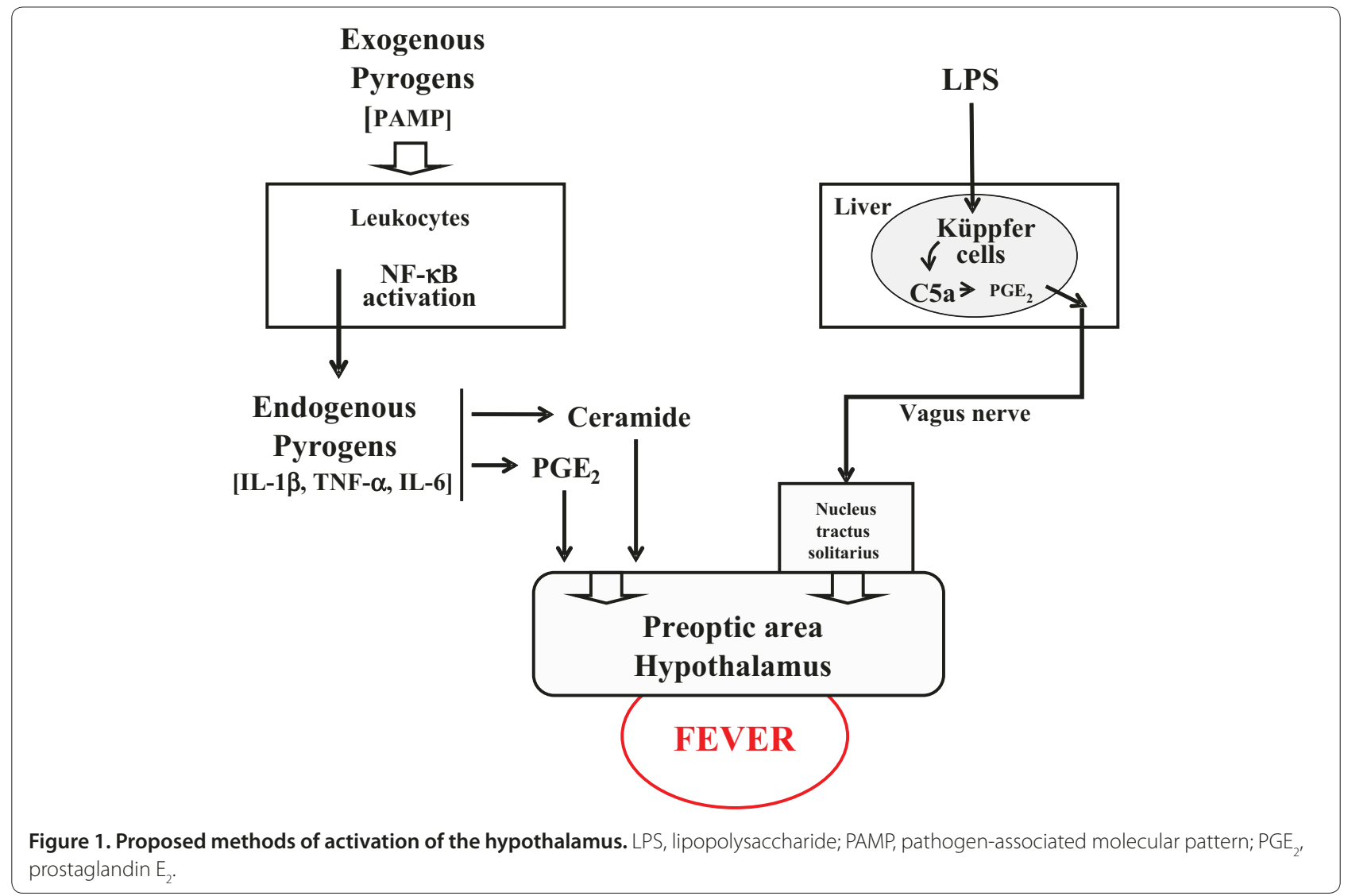

been shown among different methods of temperature measurement that better accuracy was obtained for the urinary or oesophageal temperature $[14,15]$.

Fever is a preserved phylogenetic response to a wide variety of infectious and non-infectious triggers, which induce, by different methods, upregulation of the thermostatic setpoint in the preoptic area of the hypothalamus, finally resulting in fever. Several methods of activation of the hypothalamus have been described (Figure 1). Classically, the pathogen-associated molecular patterns (called exogenous pyrogens) stimulate leukocytes, which in turn produce cytokines (called endogenous pyrogens), mainly IL-1 $\beta$, TNF $\alpha$ and IL-6 [16]. These endogenous pyrogens activate the febrile response indirectly, by inducing secretion of prostaglandin $E_{2}$ in the organum vasculosum of the lamina propria located just below the preoptic area of the hypothalamus. Two other methods are recognised. The first, recently described, is also mediated by IL- $1 \beta$ but involves ceramide production by an enzymatic pathway (neutral sphingomyelinase) [17]. Ceramide therefore acts as a second messenger in place of prostaglandin $E_{2}$, which explains the early rise in core temperature [17]. The remaining method is neuronal and independent of cytokine production. The Küppfer cells stimulated by lipopolysaccharide produce prostaglandin $E_{2}$, which in turn elicits a hypothalamic response through a neural pathway mediated by the vagus nerve and the nucleus tractus solitarius $[18,19]$. These pathophysiological considerations explain why fever may be induced by inflammation or infection.

\section{Beneficial effects of fever}

While many years of clinical observations and several published observational studies suggest fever is beneficial to the host, it is important to emphasise the lack of robust clinical evidence concerning the assessment of fever's benefits. How fever could influence outcome in septic patients is a key issue that remains debated because of the limited value of studies that included a heterogeneous population of patients with different levels of severity of sepsis. Nevertheless, a set of arguments can help enlighten this issue. Indeed, there are direct arguments that refer to the beneficial effects of fever per se and indirect arguments that reflect the noxious effects of fever suppression.

\section{Direct arguments}

\section{Fever effects on infectious agents}

Fever has an impact on microorganism growth. Human pathogen infectious agents usually grow under optimal 
temperatures of around 35 to $37^{\circ} \mathrm{C}$ [20]. In experimental meningitis, the elevated body temperature increases the pneumococci growth time in cerebral spinal fluid when compared with a blunted febrile response induced by urethane [21]. Similarly, an in vitro study on Plasmodium falciparum concluded that febrile temperatures play a role in inhibiting parasite growth [22]. Experimentally, increasing the temperature from 35 to $41.5^{\circ} \mathrm{C}$ on 432 strains of bacteria revealed a progressive rise in the activity of antimicrobial agents (17 antimicrobial agents tested) and a reduction in the minimum inhibitory concentrations [23].

\section{Effects of fever on immunity and heat shock response}

Fever is also known to modulate the cellular immune response and to induce the heat shock response. Hyperthermic preconditioning of a rat model of peritonitis reduced the severity of infection, prevented a decrease in the number of CD4 lymphocytes and B cells, and decreased the serum level of the proinflammatory cytokine TNF $\alpha$ [24]. Furthermore, other studies reported an increase in the mobility of polymorphonuclear cells, in the phagocytosis speed, in lymphocyte recruitment, in adherence of T-helper lymphocytes to L-selectin, in immunoglobulin levels and in TNF $\alpha$ cytotoxicity in response to elevated temperature [25].

Heat shock proteins are critical for cellular protection in reducing endothelial and organ damage during several stresses including fever. Recent data demonstrated that a heat shock response can downregulate the activity of NF- $\kappa B$, modulating the immune response [26]. Reduced mortality and organ injury were reported after heat pretreatment in a rat model of intra-abdominal sepsis and sepsis-induced lung injury, with increased levels of HSP-72 in the lungs and heart of the heat-treated animals [27]. More recently, in a sheep model of peritonitis, febrile animals had a longer survival time with concomitant higher HSP-70 levels when compared with the other animals [28].

\section{Clinical data}

Direct clinical evidence is supported by old studies and more recent studies. A retrospective analysis of 218 patients with Gram-negative bacilli bacteraemia reported significantly higher survival in patients who developed fever on the day of bacteraemia [29]. The mortality of patients with spontaneous bacterial peritonitis was reduced when the body temperature was $>38^{\circ} \mathrm{C}$ [30]. In the same disease, a positive correlation between body temperature increase and survival has been shown [31]. In elderly patients with community-acquired pneumonia, a higher mortality rate was observed in patients who lacked fever when compared with patients who developed a febrile response ( $29 \%$ vs. $4 \%$ ) [32]. More recently, the multicenter French AmarCand study pointed out that fever $>38.2^{\circ} \mathrm{C}$ was a protective factor in invasive Candida spp. infections in the ICU [33]. In a selected population of ICU-infected patients, both hypothermia and fever increased morbidity and mortality rates, but patients with hypothermia had a higher mortality when compared with those who had fever ( $80 \%$ vs. $47 \%$ ) [11]. In a similar selected population, Arons and colleagues reported an increased mortality in hypothermic patients. Interestingly, the inflammatory response was increased in these patients when compared with febrile patients, suggesting a protective effect of fever per se [34].

\section{Indirect arguments \\ Experimental data}

Beneficial effects of fever are reported in several experimental studies. Ectothermic desert lizards (Dipsosaurus dorsalis) infected by Aeromonas hydrophilia had a greater survival rate when they were placed in a warm environment [35]. Subsequently, in the same model, the suppression of fever by an injection of sodium salicylate was demonstrated to dramatically increase mortality [36]. Similarly, in a murine bacterial peritonitis model, increasing the core temperature by housing mice in a $35.5^{\circ} \mathrm{C}$ ambient temperature led to an improved survival rate when compared with animals placed in a cooler environment. Moreover, TNF $\alpha$ expression was suppressed in the early 48 hours and IFNY expression was delayed. Interestingly, after animal sacrifice, significantly lower concentrations of bacteria per organ were observed in animals with fever when compared with cooled animals [37].

$\mathrm{Su}$ and colleagues explored the effects of controlling fever with paracetamol or external cooling in a sheep septic shock model. The febrile animals had better respiratory function and a prolonged survival time [28]. Finally, a recent meta-analysis that included eight studies on influenza-infected animals reported an increased risk of mortality when the animals received various antipyretic treatments (odds ratio $=1.34,95 \%$ confidence interval $=1.04$ to 1.73$)[38]$.

\section{Clinical data}

Several clinical studies indirectly advocate a beneficial effect of fever. For instance, in a placebo-controlled trial, Graham and colleagues compared the effects of aspirin and paracetamol on virus shedding, immune response and clinical status in rhinovirus-infected volunteers. In the aspirin and paracetamol group, a longer duration of virus shedding and suppression of serum-neutralising antibody response were observed [5]. In addition, another randomised trial showed that treatment of fever with paracetamol in $P$. falciparum malaria-infected children prolonged the parasite clearance time when 
compared with untreated children [39]. A more recent study demonstrated that prophylactic administration of antipyretic drugs at the time of vaccination induced a delayed and lower antibody response to several vaccine antigens, although paracetamol similarly affected antibody response in children with or without fever [40]. Finally, a randomised study in febrile surgical and trauma critically ill patients to assess the impact of antipyretic therapy on infection development was interrupted after the first interim analysis, because of higher mortality in the antipyretic group (seven deaths vs. one death, $P=0.06)$. Moreover, the infection rate tended to be higher in the treated group $(4 \pm 6$ per patient vs. $3 \pm 2$ per patient, $P=0.26$ ) [41].

These indirect data reinforce the concept that fever may play a role in the survival of septic patients, although the impact of antipyretics on morbidity cannot be excluded.

\section{Detrimental effects of fever}

Even though the febrile response seems useful in the adaptive reaction to a stressful situation, it could cause several detrimental effects on clinical outcomes. Indeed, fever increases metabolic demand and consequently oxygen consumption of different organs, notably the brain and the heart, and worsens pre-existing disease. For instance, in neurological injuries, fever is now a wellrecognised factor of secondary cerebral insult and contributes to deterioration of the clinical outcome [4]. In acute ischaemic stroke, studies suggest that fever is strongly associated with significant morbidity and a mortality increase up to $20 \%[42,43]$. A similar issue is raised in traumatic brain injuries in which fever is responsible for overwhelming secondary brain injuries [44]. In neurological injuries, therefore, the control of fever is a major therapeutic axis to prevent worsening of the primary lesions, despite the lack of prospective studies that assess the impact of a normothermia strategy on the outcome [45].

Myocardial injuries are another disease category in which fever can be deleterious. Because of increased oxygen consumption, patients with underlying heart diseases, especially coronary disease and ischaemic cardiomyopathy, are more exposed to the systemic effects of fever. In a swine model of acute myocardial infarction, an elevation of body temperature up to $39^{\circ} \mathrm{C}$ provoked an increased infarct size [46]. Similarly, in febrile critically ill patients, the reduction of fever from 39 to $37^{\circ} \mathrm{C}$ induced a decrease of oxygen consumption and unloaded the cardiorespiratory system, which favoured resuscitation of patients who had limited oxygen delivery [47]. In these situations, the benefits of fever control when an infectious process is ongoing must be counterbalanced by the inherent benefits of fever. However, no clinical data are available to support such an approach.
The discomfort from fever is usually claimed to justify fever treatment, although it is not clear whether the discomfort is due to fever per se or rather to the neuroendocrine and/or metabolic response to an infectious process $[8,48]$. Similarly, the preventive treatment of fever to avoid febrile seizures in children remains a largely debated and controversial issue [6].

Finally, it has been hypothesised that fever could induce collateral tissue damage as a consequence of enhanced microbial killing mechanisms. In a mouse model of Gram-negative bacterial pneumonia, fever tended to worsen survival despite enhanced innate host defence and successful elimination of pathogens. The authors found that the reduced survival was accompanied by increased vascular pulmonary injury, enhanced accumulation of neutrophils and increased levels of cytokines in the bronchoalveolar lavage [49]. Indeed, the same process could also initiate injury to host tissues, suggesting the fact that the ultimate effect of fever is determined by the balance between accelerated pathogen clearance and collateral tissue injury. At a high fever level $\left(>40\right.$ to $\left.41^{\circ} \mathrm{C}\right)$, however, the beneficial immunomodulatory effect could be outweighed by the deleterious metabolic/inflammatory effect of fever.

\section{Side effects of antipyretic treatments}

Despite a lack of experimental and clinical data, febrile ICU patients are frequently treated to lower their fever response [50]. Methods of treatment include direct cooling and/or antipyretic medications such as nonsteroidal anti-inflammatory drugs (NSAIDs) and paracetamol. These treatments may delay early diagnosis and appropriate therapy of major infections, and they carry their own undesirable side effects (bleeding, hypotension, hepatic and renal toxicity). These consequences must be taken into account when fever-reducing therapy is initiated in critically ill patients.

\section{Paracetamol}

The most serious adverse effect of paracetamol is a lifethreatening hepatic necrosis related to overdosage. This necrosis leads to hepatocellular injury in relation to the toxic $N$-acetyl-p-benzo-quinone imine metabolite when the capacity of glutathione is exceeded. In normal use, paracetamol is safe - but it is noteworthy that acute hepatitis may occur in ICU patients who have reduced glutathione reserves, such as in alcoholics and/or malnourished patients [51]. In addition, clinical evidence suggests that the same metabolic pathway could be involved in the kidney and plays a role in analgesicassociated nephropathy [52].

Interestingly, in a randomised single-blind study, healthy volunteers who received paracetamol (4 g daily for 14 days) experienced a significant increase of serum 
Table 1. Summary of the beneficial and detrimental effects of fever

\begin{tabular}{|c|c|}
\hline Beneficial effects & Detrimental effects \\
\hline On invading microorganism & \multirow{2}{*}{$\begin{array}{l}\text { Increased metabolic demand and oxygen consumption (myocardial and } \\
\text { neurological injuries) }\end{array}$} \\
\hline Reduced growth/prolonged growth time & \\
\hline Increased antibiotic sensitivity/reduced minimal inhibitory concentration & Source of patients' discomfort? \\
\hline Accelerated immune response & Children's seizures? (Controversial) \\
\hline Increased mobility of polymorphonuclear cells & \multirow[t]{8}{*}{ Collateral tissue damage? } \\
\hline Increased phagocytosis & \\
\hline Increased T-helper cell adherence & \\
\hline Prevention of lymphocytes cell reduction (CD4T cells and B cells) & \\
\hline Attenuated immune response/protection against the collateral damage & \\
\hline Increased heat shock protein causing a decrease of NF-KB & \\
\hline Reduced TNFa & \\
\hline Reduced IFNy & \\
\hline
\end{tabular}

alanine aminotransferases when compared with placebo [53]. The incidence of maximum alanine aminotransferase increased more than three times the upper normal value in approximately one-third of treated patients. The clinical significance of the alanine aminotransferase elevation is unclear but the implication in ICU patients warrants further investigation.

In contrast to NSAIDs, paracetamol usually is not considered to influence platelet function. However, intravenous paracetamol has been shown to inhibit platelet cyclooxygenase- 1 in a dose-dependent anti-aggregatory manner in healthy volunteers [54].

Finally, the potential for paracetamol to produce cardiovascular toxicity is low. Blood pressure was significantly reduced, however, after administration of $1 \mathrm{~g}$ paracetamol by mouth or feeding tube [55]. More recently, in 14 febrile critically ill patients, Hersch and colleagues administered an intravenous bolus of propacetamol, $2 \mathrm{~g}$ over 15 to 20 minutes, and showed that blood pressure was significantly decreased 15 minutes after infusion. Noteworthy, the systolic blood pressure dropped to $<90 \mathrm{mmHg}$ in approximately one-third of patients, requiring both fluid administration and norepinephrine escalade or infusion [56].

\section{Nonsteroidal anti-inflammatory drugs}

The main side effect of NSAIDs, gastrointestinal bleeding, derives from their capacity to inhibit cyclooxygenase. NSAIDs with a high affinity for cyclooxygenase- 1 are 10 times more likely to induce a gastrointestinal event such as mucosal lesions, a perforated ulcer or gastrointestinal bleeding [57]. NSAIDs are also known to have adverse effects on kidney function through inhibition of prostaglandin synthesis, notably when used in situations in which the renin-angiotensin system is stimulated, such as volume depletion, pre-existing renal failure or concomitant nephrotoxic agents [58,59]. Of note, some NSAIDs may cause vasospasm in patients who have previous coronary artery disease [60].

Risk factors for severe NSAID-induced adverse effects include high dosage, advanced age, concomitant use of steroids or anticoagulants and short duration of therapy, situations that are frequently observed in ICU patients [61].

\section{Physical methods}

Physical cooling is usually indicated for the treatment of hyperthermia and fever, but its use remains controversial because of the propensity to induce sympathetic activation, cutaneous vasoconstriction and shivering [62]. As a first consequence, in febrile patients the capacity of external cooling to lower the core temperature may be limited by thermoregulatory mechanisms aiming to maintain the elevated body temperature [63]. Second, if shivering is present, physical cooling causes a rise in oxygen consumption and may be deleterious. In volunteers, induction of fever and active external cooling increased oxygen consumption up to $40 \%$ and was associated with a significant increase in catecholamine levels [62]. Therefore, when external cooling is used in the ICU, it is frequently necessary to inhibit shivering by administering therapeutic myorelaxant medication [47]. Moreover, the use of a hypothermia blanket in febrile ICU patients has been shown to induce a large temperature fluctuation and frequent rebound hypothermia [64].

\section{Extracorporeal mechanisms}

Although techniques such as extracorporeal membrane oxygenation, haemodialysis or plasmapheresis are not specifically used to decrease fever, they generally lead to 
normothermia in febrile patients. However, the impact of such consequences remains elusive.

\section{Conclusion}

In light of these concerns, healthcare providers have to consider carefully whether to use an antipyretic technique and/or agent in ICU patients by weighing up the risks and the possible benefits.

\section{Conclusion}

Fever is a basic response triggered by an infectious or a non-infectious process. The balance of benefit to harm of fever in septic ICU patients is complex. This balance is likely to be dependent on the stage and severity of the infection, on the intensity of the immune response, on the extent of systemic inflammatory response-induced collateral tissue damage as well as on the underlying physiological reserve of the patient (Table 1). On the other hand, the widespread use of antipyretic methods in ICU patients is not supported by clinical data and fever control may be harmful, particularly when an infectious disease is progressing. We await appropriately designed, prospective randomised trials to define patient groups likely to benefit from or be harmed by antipyretic treatment. The decision to introduce an antipyretic therapy should be well balanced according to the presence of neurological injuries and/or underlying cardiac disease and the absence of sepsis.

\section{Abbreviations}

HSP, heat shock protein; ICU, intensive care unit; IFN, interferon; IL, interleukin; NF, nuclear factor; NSAID, nonsteroidal anti-inflammatory drug; TNF, tumour necrosis factor.

\section{Competing interests}

The authors declare that they have no competing interests.

\section{Author details}

'Service d'Anesthésie-Réanimation 1, Hôpital Pontchaillou, 2 rue Henri Le Guilloux, 35000 Rennes, France. ${ }^{2}$ nnserm unit 991, Team 2, 2 rue Henri Le Guilloux, 35000 Rennes, France. ${ }^{3}$ Université de Rennes 1, Faculté de Médecine, Rennes, France.

Published: 7 June 2011

\section{References}

1. Mackowiak PA, Wasserman SS, Levine MM: A critical appraisal of $98.6^{\circ} \mathrm{F}$, the upper limit of the normal body temperature, and other legacies of Carl Reinhold August Wunderlich. JAMA 1992, 268:1578-1580.

2. Circiumaru B, Baldock $G$, Cohen J: A prospective study of fever in the intensive care unit. Intensive Care Med 1999, 25:668-673.

3. Laupland KB: Fever in the critically ill medical patient. Crit Care Med 2009, 37:S273-S278

4. Polderman $\mathrm{KH}$ : Induced hypothermia and fever control for prevention and treatment of neurological injuries. Lancet 2008, 371:1955-1969.

5. Graham NM, Burrell CJ, Douglas RM, Debelle P, Davies L: Adverse effects of aspirin, acetaminophen, and ibuprofen on immune function, viral shedding, and clinical status in rhinovirus-infected volunteers. J Infect Dis 1990, 162:1277-1282.

6. Fetveit A: Assessment of febrile seizures in children. Eur J Pediatr 2008, 167:17-27.

7. Lenhardt R, Negishi C, Sessler DI, Ozaki M, Ettinger K, Bastanmehr H, Lobo E:
The effect of pyrogen administration on sweating and vasoconstriction thresholds during desflurane anesthesia. Anesthesiology 1999,

90:1587-1595

8. Gozzoli V, Schöttker P, Suter PM, Ricou B: Is it worth treating fever in intensive care unit patients? Preliminary results from a randomized trial of the effect of external cooling. Arch Intern Med 2001, 161:121-123.

9. Pierrakos C, Vincent J: Sepsis biomarkers: a review. Crit Care 2010, 14:R15.

10. Laupland KB, Shahpori R, Kirkpatrick AW, Ross T, Gregson DB, Stelfox HT: Occurrence and outcome of fever in critically ill adults. Crit Care Med 2008, 36:1531-1535.

11. Peres Bota D, Lopes Ferreira F, Mélot C, Vincent JL: Body temperature alterations in the critically ill. Intensive Care Med 2004, 30:811-816.

12. O'Grady NP, Barie PS, Bartlett JG, Bleck T, Carroll K, Kalil AC, Linden P, Maki DG, Nierman D, Pasculle W, Masur H: Guidelines for evaluation of new fever in critically ill adult patients: 2008 update from the American College of Critical Care Medicine and the Infectious Diseases Society of America. Crit Care Med 2008, 36:1330-1349.

13. Dellinger RP, Levy MM, Carlet JM, Bion J, Parker MM, Jaeschke R, Reinhart K, Angus DC, Brun-Buisson C, Beale R, Calandra T, Dhainaut JF, Gerlach H, Harvey M, Marini JJ, Marshall J, Ranieri M, Ramsay G, Sevransky J, Thompson BT, Townsend S, Vender JS, Zimmerman JL, Vincent JL: Surviving Sepsis Campaign: international guidelines for management of severe sepsis and septic shock: 2008. Crit Care Med 2008, 36:296-327.

14. Moran JL, Peter JV, Solomon PJ, Grealy B, Smith T, Ashforth W, Wake M, Peake $S L$, Peisach AR: Tympanic temperature measurements: are they reliable in the critically ill? A clinical study of measures of agreement. Crit Care Med 2007, 35:155-164.

15. Lefrant J, Muller L, de La Coussaye JE, Benbabaali M, Lebris C, Zeitoun N, Mari C, Saïssi G, Ripart J, Eledjam J: Temperature measurement in intensive care patients: comparison of urinary bladder, oesophageal, rectal, axillary, and inguinal methods versus pulmonary artery core method. Intensive Care Med 2003, 29:414-418.

16. Netea MG, Kullberg BJ, Van der Meer JW: Circulating cytokines as mediators of fever. Clin Infect Dis 2000, 31(Suppl 5):S178-S184.

17. Sanchez-Alavez M, Tabarean IV, Behrens MM, Bartfai T: Ceramide mediates the rapid phase of febrile response to IL-1 $\beta$. Proc Natl Acad Sci U S A 2006 103:2904-2908.

18. Perlik V, Li Z, Goorha S, Ballou LR, Blatteis CM: LPS-activated complement, not LPS per se, triggers the early release of $\mathrm{PGE}_{2}$ by Kupffer cells. Am J Physiol Regul Integr Comp Physiol 2005, 289:R332-R339.

19. Romanovsky AA, Ivanov Al, Székely M: Neural route of pyrogen signaling to the brain. Clin Infect Dis 2000, 31(Suppl 5):S162-S167.

20. Prescott LM: Microbiology. Boston, MA: WCB/McGraw-Hill; 1999.

21. Small PM, Täuber MG, Hackbarth CJ, Sande MA: Influence of body temperature on bacterial growth rates in experimental pneumococcal meningitis in rabbits. Infect Immun 1986, 52:484-487.

22. Kwiatkowski D: Febrile temperatures can synchronize the growth of Plasmodium falciparum in vitro. J Exp Med 1989, 169:357-361.

23. Mackowiak PA, Marling-Cason M, Cohen RL: Effects of temperature on antimicrobial susceptibility of bacteria. J Infect Dis 1982, 145:550-553.

24. Ozveri ES, Bekraki A, Cingi A, Yuksel M, Demiralp EE, Yegen BC, Aktan AO: The effect of hyperthermic preconditioning on the immune system in rat peritonitis. Intensive Care Med 1999, 25:1155-1159.

25. Hasday JD, Singh IS: Fever and the heat shock response: distinct, partially overlapping processes. Cell Stress Chaperones 2000, 5:471-480.

26. Sun Z, Andersson R: NF-KB activation and inhibition: a review. Shock 2002, 18:99-106.

27. Villar J, Ribeiro SP, Mullen JB, Kuliszewski M, Post M, Slutsky AS: Induction of the heat shock response reduces mortality rate and organ damage in a sepsis-induced acute lung injury model. Crit Care Med 1994, 22:914-921.

28. Su F, Nguyen ND, Wang Z, Cai Y, Rogiers P, Vincent J: Fever control in septic shock: beneficial or harmful? Shock 2005, 23:516-520.

29. Bryant RE, Hood AF, Hood CE, Koenig MG: Factors affecting mortality of Gram-negative rod bacteremia. Arch Intern Med 1971, 127:120-128.

30. Weinstein MP, lannini PB, Stratton CW, Eickhoff TC: Spontaneous bacterial peritonitis. A review of 28 cases with emphasis on improved survival and factors influencing prognosis. Am J Med 1978, 64:592-598.

31. Hoefs JC, Canawati HN, Sapico FL, Hopkins RR, Weiner J, Montgomerie JZ: Spontaneous bacterial peritonitis. Hepatology 1982, 2:399-407.

32. Ahkee S, Srinath L, Ramirez J: Community-acquired pneumonia in the elderly: association of mortality with lack of fever and leukocytosis. South 
Med J 1997, 90:296-298.

33. Leroy O, Gangneux J, Montravers P, Mira J, Gouin F, Sollet J, Carlet J, Reynes J, Rosenheim M, Regnier B, Lortholary O: Epidemiology, management, and risk factors for death of invasive Candida infections in critical care: a multicenter, prospective, observational study in France (2005-2006). Crit Care Med 2009, 37:1612-1618.

34. Arons MM, Wheeler AP, Bernard GR, Christman BW, Russell JA, Schein R, Summer WR, Steinberg KP, Fulkerson W, Wright P, Dupont WD, Swindell BB: Effects of ibuprofen on the physiology and survival of hypothermic sepsis. Ibuprofen in Sepsis Study Group. Crit Care Med 1999, 27:699-707.

35. Kluger MJ, Ringler DH, Anver MR: Fever and survival. Science 1975, 188:166-168.

36. Bernheim HA, Kluger MJ: Fever: effect of drug-induced antipyresis on survival. Science 1976, 193:237-239.

37. Jiang Q, Cross AS, Singh IS, Chen TT, Viscardi RM, Hasday JD: Febrile core temperature is essential for optimal host defense in bacterial peritonitis. Infect Immun 2000, 68:1265-1270.

38. Eyers $S$, Weatherall $M$, Shirtcliffe P, Perrin K, Beasley R: The effect on mortality of antipyretics in the treatment of influenza infection: systematic review and meta-analysis. J R Soc Med 2010, 103:403-411.

39. Brandts CH, Ndjavé M, Graninger W, Kremsner PG: Effect of paracetamol on parasite clearance time in Plasmodium falciparum malaria. Lancet 1997 350:704-709.

40. Prymula R, Siegrist C, Chlibek R, Zemlickova H, Vackova M, Smetana J, Lommel P, Kaliskova E, Borys D, Schuerman L: Effect of prophylactic paracetamol administration at time of vaccination on febrile reactions and antibody responses in children: two open-label, randomised controlled trials. Lancet 2009, 374:1339-1350.

41. Schulman Cl, Namias N, Doherty J, Manning RJ, Li P, Alhaddad A, Lasko D, Amortegui J, Dy CJ, Dlugasch L, Baracco G, Cohn SM: The effect of antipyretic therapy upon outcomes in critically ill patients: a randomized, prospective study. Surg Infect (Larchmt) 2005, 6:369-375

42. Saini M, Saqqur M, Kamruzzaman A, Lees KR, Shuaib A: Effect of hyperthermia on prognosis after acute ischemic stroke. Stroke 2009, 40:3051-3059.

43. Hajat C, Hajat S, Sharma P: Effects of poststroke pyrexia on stroke outcome: a meta-analysis of studies in patients. Stroke 2000, 31:410-414.

44. Jiang J, Gao G, Li W, Yu M, Zhu C: Early indicators of prognosis in 846 cases of severe traumatic brain injury. J Neurotrauma 2002, 19:869-874.

45. Badjatia N: Hyperthermia and fever control in brain injury. Crit Care Med 2009, 37:S250-S257.

46. Duncker DJ, Klassen $\mathrm{CL}$, IshibashiY, Herrlinger SH, PavekTJ, Bache RJ. Effect of temperature on myocardial infarction in swine. Am J Physiol 1996, 270:H1189-H1199.

47. Manthous CA, Hall JB, Olson D, Singh M, Chatila W, Pohlman A, Kushner R, Schmidt GA, Wood LD: Effect of cooling on oxygen consumption in febrile critically ill patients. Am J Respir Crit Care Med 1995, 151:10-14.

48. Betts RF, Chapman SW, Penn RL: Reese and Betts'A Practical Approach to Infectious Diseases. Philadelphia, PA: Lippincott Williams \& Wilkins; 2003.

49. Rice P, Martin E, He J, Frank M, DeTolla L, Hester L, O'Neill T, Manka C, Benjamin I, Nagarsekar A, Singh I, Hasday JD: Febrile-range hyperthermia augments neutrophil accumulation and enhances lung injury in experimental Gramnegative bacterial pneumonia. J Immuno/ 2005, 174:3676-3685.

50. Bernard GR, Wheeler AP, Russell JA, Schein R, Summer WR, Steinberg KP, Fulkerson WJ, Wright PE, Christman BW, Dupont WD, Higgins SB, Swindell BB: The effects of ibuprofen on the physiology and survival of patients with sepsis. The Ibuprofen in Sepsis Study Group. N Engl J Med 1997, 336:912-918

51. Moling O, Cairon E, Rimenti G, Rizza F, Pristerá R, Mian P: Severe hepatotoxicity after therapeutic doses of acetaminophen. Clin Ther 2006, 28:755-760.

52. Blantz RC: Acetaminophen: acute and chronic effects on renal function Am J Kidney Dis 1996, 28:S3-S6.

53. Watkins PB, Kaplowitz N, Slattery JT, Colonese CR, Colucci SV, Stewart PW, Harris SC: Aminotransferase elevations in healthy adults receiving 4 grams of acetaminophen daily: a randomized controlled trial. JAMA 2006, 296:87-93.

54. Munsterhjelm E, Munsterhjelm NM, Niemi TT, Ylikorkala O, Neuvonen PJ, Rosenberg PH: Dose-dependent inhibition of platelet function by acetaminophen in healthy volunteers. Anesthesiology 2005, 103:712-717.

55. Boyle M, Hundy S, Torda TA: Paracetamol administration is associated with hypotension in the critically ill. Aust Crit Care 1997, 10:120-122.

56. Hersch M, Raveh D, Izbicki G: Effect of intravenous propacetamol on blood pressure in febrile critically ill patients. Pharmacotherapy 2008, 28:1205-1210.

57. Gabriel SE, Jaakkimainen L, Bombardier C: Risk for serious gastrointestinal complications related to use of nonsteroidal anti-inflammatory drugs. A meta-analysis. Ann Intern Med 1991, 115:787-796.

58. Pirson Y, van Ypersele de Strihou C: Renal side effects of nonsteroidal antiinflammatory drugs: clinical relevance. Am J Kidney Dis 1986, 8:338-344.

59. Whelton A: Nephrotoxicity of nonsteroidal anti-inflammatory drugs: physiologic foundations and clinical implications. Am J Med 1999, 106:13S-24S

60. Greisman LA, Mackowiak PA: Fever: beneficial and detrimental effects of antipyretics. Curr Opin Infect Dis 2002, 15:241-245

61. Wolfe MM, Lichtenstein DR, Singh G: Gastrointestinal toxicity of nonsteroidal antiinflammatory drugs. N Engl J Med 1999, 340:1888-1899.

62. Lenhardt R, Negishi C, Sessler DI, Vuong K, Bastanmehr H, Kim JS, Bjorksten AR: The effects of physical treatment on induced fever in humans. Am J Med 1999, 106:550-555.

63. Kurz A, Sessler DI, Christensen R, Dechert M: Heat balance and distribution during the core-temperature plateau in anesthetized humans. Anesthesiology 1995, 83:491-499.

64. O'Donnell J, Axelrod P, Fisher C, Lorber B: Use and effectiveness of hypothermia blankets for febrile patients in the intensive care unit. Clin Infect Dis 1997, 24:1208-1213.

doi:10.1186/cc10097

Cite this article as: Launey Y, et al:: Clinical review: Fever in septic ICU

patients -friend or foe? Critical Care 2011, 15:222 